\title{
Fotografias escolares: a leitura de imagens na história da escola primária
}

\section{School Photographs: the image reading in the history of primary school}

\author{
Rosa Fátima de Souza*
}

\begin{abstract}
RESUMO
Este estudo compreende a leitura de fotografias, especificamente, fotografias escolares referentes ao ensino primário na cidade de Campinas, no período de 1897 a 1950. Com base em um acervo constituído de 55 imagens, analisa quatro categorias de fotografias: arquitetura escolar, classes de alunos, corpo docente e atividades escolares; assinalando o discurso sobre a escola, os contextos humanos e as relações sociais reveladas pelas imagens. O texto destaca, também, a relevância da documentação iconográfica para o estudo da História da Educação, em especial, o estudo das instituições educativas.

Palavras-chave: leitura de imagens, História da Escola Primária, fotografias escolares, fontes iconográficas
\end{abstract}

\begin{abstract}
This research consists in photograph reading, more specifically, school photographs related to primary teaching in the city of Campinas, between 1897 and 1950. It is based on a heritage constituted of 55 images that analyzes four categories of photographs: school architecture, student classes, teaching body and school activities, these categories illustrate the discourse about school, human contexts and social relations revealed by those images. The text also focuses the iconography documentation relevance for History of Education research, specially, about educational institutions.

Key-words: image reading, Fundamental School History, school photographs, iconography sources.
\end{abstract}

\footnotetext{
*Doutora em História da Educação, Professora do Departamento de Ciências da Educação da Faculdade de Ciências e Letras de Araraquara/Unesp. rosa@ fclar.unesp.br
} 
A pesquisa que deu origem a este texto teve por finalidades reconstituir as demandas pela educação elementar em Campinas no período de 1897 a 1950 e investigar a história institucional dos primeiros Grupos Escolares instalados na cidade. Essa modalidade de escola primária foi implantada, pela primeira vez no Brasil, no Estado de São Paulo em $1893^{1}$ e correspondeu, na época, a um novo modelo de organização administrativopedagógica da escola primária com base na graduação escolar - classificação dos alunos por grau de adiantamento -, no estabelecimento de programas de ensino e da jornada escolar, na reunião de vários professores e várias salas de aula em um mesmo edifício-escola para atender a um grande número de crianças, na divisão do trabalho e em critérios de racionalização, uniformidade e padronização do ensino. Este tipo de escola foi considerado o mais adequado para a escolarização em massa e tornou-se, em pouco tempo, o modelo predominante de escola primária em São Paulo e no país.

A história dos grupos escolares de Campinas, como se tentou construir nesta investigação, evidenciou os problemas e percalços que envolvem a história das instituições educativas. Como bem assinala Magalhães, a renovação nesse campo da História da Educação tem implicado a "problematização da relação das instituições educativas com o meio sociocultural envolvente e pelos questionamentos e (re)construção das representações simbólicas das práticas educativas que marcam a sua identidade" (1996, p. 2). Nesse sentido, a investigação buscou considerar esses vários movimentos, isto é, compreender a relação de uma modalidade específica de escola primária com a sociedade da época e ao mesmo tempo explicitar os aspectos internos dessas instituições escolares, ou seja, a organização administrativo-pedagógica e os aspectos relacionados à cultura escolar.

Para o estudo das instituições educativas foi privilegiado o levantamento de fontes e dados em arquivos escolares. ${ }^{2}$ Em porões, no meio de poeira e quinquilharias, em arquivos morto, em um dos armários das secretarias, às vezes em cofres sigilosamente guardados ou em alguns cantos de bibliotecas emergiram vários documentos: Livros de Matrícula, Livro Ponto, Livros de Atas de Exames, Livros de Termo de Compromisso, Livros de Nomeações e Licenças, Livro de Termo de Visitas, Livro de Atas de

\footnotetext{
${ }^{1}$ Criação dos grupos escolares: Lei no 169 , de 7 de agosto de 1893 . Coleção de Leis e Decretos do Estado de São Paulo. Estudo detalhado sobre as origens dessa modalidade de escola primária encontra-se em SOUZA, R. F. Templos De Civilização: a implantação dos grupos escolares no Estado de São Paulo (1890-1910). São Paulo: Editora Unesp, 1998.

${ }^{2}$ Para as finalidades do estudo proposto foram selecionados os sete primeiros grupos escolares instalados em Campinas a saber: GE "Francisco Glicério" (1897), GE "Dr. Quirino dos Santos" (1900), GE “Artur Segurado" (1910), GE “Orozimbo Maia” (1923), GE “Antônio Vilela Junior" (1925), GE “Dom Barreto” (1925), GE "Dona Castorina Cavalheiro” (1925).
} 
Reuniões Mensais, além de históricos dos grupos escolares, livros de escrituração, livros de correspondências e umas tantas fotografias, a maioria delas sem nomes dos figurantes, sem datas e sem qualquer identificação.

Em quantidade e correspondendo a cronologia variada, essa documentação fragmentada, diacrônica e dispersa representa alguns poucos vestígios do itinerário de vida das escolas públicas conservados em precárias condições e salvaguardados pelo benefício da vontade de alguns. Tal documentação, quase toda ela de natureza administrativa, revela o sentido do que as instituições educativas têm privilegiado ou podido preservar em seus escassos espaços. É assim que os registros das aulas, os semanários e diários de lições dos professores, os cadernos, as provas e os trabalhos dos alunos, os livros didáticos, os cartazes, os materiais escolares, perderam-se pelo tempo, dificultando, dessa forma, investigações sobre a ação dos atores e as práticas de ensino. Contudo, os arquivos escolares oferecem um conjunto de fontes relevantes para se investigar a política de acesso (oferta e demanda), as formas de recrutamento e seleção de alunos e professores, bem como a caracterização do corpo docente e discente.

Além dessas fontes, foram utilizados jornais (Diário do Povo, Cidade de Campinas, Correio Popular), Almanaques, Ofícios da Prefeitura e Atas da Câmara Municipal, relatórios dos diretores dos grupos escolares, Anuários do Ensino do Estado de São Paulo, Coleção de Leis e Decretos do Estado de São Paulo e periódicos educacionais (Revista de Ensino e Revista da Educação).

Nesse conjunto diversificado de fontes, destacam-se as fotografias escolares, testemunho precário, porém evocativo de um modo de ser e representar a escola primária.

Durante a realização da pesquisa, foi possível reunir um acervo de 55 fotografias escolares. Ao utilizá-las como mais uma fonte de pesquisa, não foram desconsideradas as dificuldades da análise de fotografias e o seu uso na pesquisa histórica. Quando a vida escolar torna-se tema do olhar fotográfico? Quando e por que se fotografam cenas escolares? Quem conserva essas imagens e por que o fazem? O que nos revelam essas imagens?

Este texto compreende uma tentativa de respostas a estas questões. Constitui, ainda, um exemplo de leitura de imagens de fotografias escolares destacando assim, a relevância da documentação iconográfica para a História da Educação.

A maioria das imagens foram encontradas nos arquivos das escolas pesquisadas, outras no acervo iconográfico do Centro de Memória-Unicamp e algumas em acervos particulares. Essas imagens foram reproduzidas em tamanho $18 \times 12$, em preto e branco e papel fosco. 


\section{O desafio da leitura de imagens}

Cada fotografia testemunha a inexorável dissolução do tempo, precisamente por selecionar e fixar um determinado momento.

Sontag

A potencialidade do uso de fotografias no estudo da história tem sido enfatizada por vários autores como KOSSOY (1995), LEITE (1993, 1998), FABRIS (1991), BARROS (1992).

Para esses autores, a leitura de imagens requer uma "alfabetização do olhar", isto é, para a compreensão da imagem é preciso submetê-la a uma crítica que leve em consideração a interação fotógrafo, a tecnologia empregada na produção da fotografia e o objeto registrado. Portanto, a análise exige uma crítica externa, isto é, das condições de produção da fotografia e uma crítica interna relacionada ao conteúdo da imagem (LEITE, 1993, p. 45). A crítica ao conteúdo, por sua vez, demanda uma análise dos contextos humanos e das relações sociais subjacentes à imagem fotográfica.

Além disso, é preciso atentar para as múltiplas faces e realidades da imagem fotográfica como nos adverte KOSSOY (1998). Esse autor chama a atenção para as dimensões da fotografia como memória e representação, fruto de uma elaboração cultural, estética e técnica. Para ele, a compreensão da imagem passa pela desmontagem do processo de construção da representação, o que significa considerar também os usos ou aplicações que teve a imagem e as "leituras" que dela fazem os receptores.

O desafio para o pesquisador que busca utilizar a fotografia como objeto de estudo reside justamente na interpretação. Enquanto receptor da imagem, ele não pode desconsiderar os mecanismos implicados em sua recepção.

A fotografia, adverte-nos SONTAG (1986), armazena o mundo e incita ao armazenamento. Fixa um determinado momento e oferece "provas", um testemunho de um fato ou acontecimento; no entanto, em sua relação com a verdade, a fotografia também se constitui em uma interpretação do mundo.

$\mathrm{Na}$ memória das escolas públicas, as fotografias inscrevem-se na imanência do tempo presente, nos acontecimentos significativos para professores, alunos e funcionários partícipes dessa temporalidade do agora, e assim, ela se constitui em um instrumento de memória institucional e de recordação, e poucas vezes, como instrumento de história. Dessa forma, o anonimato, a ausência de datas e nomes que as identifiquem são indicativos de uma funcionalidade que se inscreve na ordem afetiva dos significados compartilhados e escapa à lógica do documento e do arquivo. 
As fotografias escolares constituem um gênero de fotografias muito difundido a partir do início do século XX, combinado com outros gêneros como os retratos de família, as fotografias de paisagens urbanas, de arquiteturas e os cartões-postais. Entre os diversos tipos de conteúdo temático retratados, o mais popular é a foto de classe. Produzidas com uma finalidade comercial, essas fotografias compreendem um objeto-mercadoria para a recordação.

Outros temas foram identificados no acervo: fotografias do corpo docente, da arquitetura escolar, de cenas de salas de aula ou de atividades escolares. A homogeneidade e a uniformização são características dos retratos escolares, cujo enquadramento, disposição formal, ângulos, focalização e planos, são semelhantes em diferentes épocas e em diferentes instituições educativas. Há, portanto, uma certa identidade e representação padronizada dessas imagens.

Para que finalidades são tiradas essas fotografias? Por que e por quem são conservadas?

Pela análise do acervo aqui considerado, pode-se dizer que as fotografias escolares guardam fortes vínculos entre a memória familiar (o álbum de família) e a memória institucional. Como afirma Magalhães:

\begin{abstract}
As instituições educativas, como as pessoas são portadoras de uma memória. Uma memória factual, assente na transmissão oral, uma memória fixista e por vezes justificativa e marcada por exageros de vária ordem. Uma memória gerada por contraposição com outras memórias, que corre ao ritmo do tempo - o tempo das pessoas, o tempo das gerações. Uma memória que encalha no acontecimento. Uma memória em torno do fabuloso e do heróico. Uma memória ritualista e comemorativa. E esta é uma realidade que o historiador não pode ignorar. As instituições educativas, se transmitem uma cultura - a cultura escolar, não deixam de produzir culturas. (1996, p. 9)
\end{abstract}

Em relação às fotografias de classes escolares, o surgimento e difusão desse tipo de fotografia vincula-se à disseminação do valor social da escola na sociedade brasileira. Especialmente, as fotos de classes atendem a essa representação simbólica, por meio da qual, a turma de alunos corresponde à classe, à série, cujo encerramento do ano letivo compreende um momento digno de ser registrado e recordado. O período escolar, "os tempos de escola", converte-se em um momento da trajetória de vida da criança e da família bastante significativo. Ao lado dos colegas, do professor ou da 
professora e às vezes do diretor, cada aluno e a classe enquanto coletivo simbolizam o próprio sentido social e cultural da escola. Os pais ou responsáveis pelas crianças são o público alvo para o consumo desse tipo de fotografia que para muitos faz parte do álbum de família.

Além das fotos de classes, encontramos grupos de professores, fachadas de escolas, solenidades, encontros de autoridades do ensino, inaugurações, exposições escolares, aulas de educação física, salas de aula. Essas imagens mais fluidas quanto ao conteúdo e destinação, retratam momentos especiais da vida escolar, instantes congelados de uma trajetória institucional. Essas imagens podem ter sido produzidas como recordação individual, mas também, podem ter sido tiradas com a finalidade de registrar eventos e situações importantes para a preservação da memória da instituição. Tais acontecimentos, fruto do trabalho e da participação dos alunos, professores e funcionários da escola, revestem-se de significados afetivos e emocionais. Na leitura de imagens, esta primeira realidade segundo KOSSOY (1998) é a mais difícil de apreender, ou seja, os sentimentos, os padrões de comportamento, as normas sociais, as intenções de cada um do grupo retratado.

Estas reflexões decorrem das observações feitas a partir dos acervos onde foram localizadas as fotografias. A maioria delas, em número de 44 , foram encontradas nos arquivos escolares. Embora tenham permanecido na instituição, a identificação é extremamente precária, o mesmo ocorre com a conservação. Nesse caso, se há uma preocupação com a preservação da memória, ela não se faz mediante o registro sistemático (identificação escrita), mas é totalmente dependente dos referentes e da transmissão oral. Enquanto há na escola pessoas que se recordam dos acontecimentos retratados ou dos fotografados, sobressai um pouco mais o conteúdo latente da fotografia. No entanto, o desaparecimento dos referentes emudece a imagem que sobrevive apenas em seu conteúdo manifesto.

As fotografias encontradas no acervo do Centro de MemóriaUnicamp, em número de quatro, fazem parte de duas coleções: uma do Instituto Agronômico e outra, de um conservador particular, o fotógrafo Geraldo Sesso Junior. Nelas, também, encontram-se poucos dados de identificação. Na primeira coleção, ressalta-se o uso de fotografias como registro da ação dos órgãos públicos e, no caso da segunda, a finalidade comercial da produção do retrato.

Nos acervos particulares (sete imagens), as fotografias escolares fazem parte do álbum de família, objeto impregnado de afetividade e recordação. $\mathrm{O}$ retrato serve como pretexto para a evocação de um passado constituído de muitas outras imagens. Nos relatos feitos por ex-alunos, emergem trajetórias de vida misturadas com a memória de uma cultura 
escolar. Esta memória, espacializada nos contornos da escola como lugar, refere-se aos comportamentos dos professores, à disciplina, ao convívio com os colegas. Essas relações sociais inscritas na cultura escolar sobrelevam a fotografia como representação. Significa dizer que as imagens expressam um padrão identitário da escola enquanto instituição educativa cujo imaginário social é reforçado por comportamentos, símbolos, práticas e ritos, tais como, o uniforme, a aula, a bandeira, a arquitetura escolar, a sala de aula.

Portanto, que revelam as fotografias escolares?

Elas são a expressão da forma escolar - uma maneira de ser e comportar na escola -, representações de uma cultura institucional veiculadora de conhecimentos, valores, normas e símbolos considerados legítimos. Elas representam singularidades e identidades compartilhadas.

\section{A arquitetura escolar: espaço institucional, lugar de memória}

A monumental arquitetura escolar paulista, edificada nas primeiras décadas republicanas, é representativa do significado político e sociocultural atribuído à educação popular nessa época. De fato, data desse período a constituição dos primeiros edifícios especialmente construídos para a escola primária, dotando-a de uma identidade espacial. As fotografias de edifícios escolares registram a composição arquitetônica e revelam significados múltiplos que envolvem estas instituições. A produção dessas imagens atendeu a diferentes finalidades.

No início do século, elas se popularizaram juntamente com a difusão dos cartões-postais. Nesse período, disseminou o gosto, a produção e a comercialização de fotografias de vistas da cidade. Como assinala Lima:

\footnotetext{
Se o retrato representou para a classe burguesa em ascensão a possibilidade de expressar sua individualidade, as vistas, por sua vez, expressam a conquista do espaço urbano: os edifícios destinados a abrigar as atividades e instituições da burguesia bem como as remodelações urbanísticas segundo a concepção burguesa, poderão graças à fotografia, serem eternizados e divulgados universalmente. (1991, p. 66)
}

As escolas, juntamente com as ferrovias, as indústrias, os edifícios públicos, compõem o cenário do universo urbano, signo de modernidade, transformação e progresso social, cujo registro fotográfico contribui para a sua eternização e vulgarização. Em álbuns ou postais, as fotografias de vistas urbanas invadem também os almanaques, as revistas, os livros. Dessa forma, 
como esclarece Lima "comparado ao retrato, o consumo de vistas revela-se não só mais acessível às classes populares, como capaz de atingir um espectro mais amplo da sociedade abarcando desde a correspondência pessoal até a divulgação oficial do país" (LIMA, 1991, p. 78).

Trata-se, portanto, de uma forma particular e ao mesmo tempo ampliada de difusão da fotografia.

Campinas no início do século, assistiu a essa divulgação e consumo de fotografias de vistas urbanas. Na coleção de figurinhas de um colecionador particular, referente à primeira década do século XX, é possível encontrar imagens que atestam o desenvolvimento e a importância da cidade. As ruas mais famosas: 13 de Maio, Andrade Neves, Barão de Jaguara, Dr. Quirino. As instituições: a Beneficência Portuguesa, o Instituto Agronômico, o Circolo Italiani Uniti, o Teatro São Carlos, o mercado, a cadeia, a estação ferroviária. As escolas: o Liceu de Artes e Ofícios, o Ginásio e o $1^{\circ}$ Grupo Escolar, denominado popularmente na época de Escola Modelo. ${ }^{3}$

As fotografias de edifícios escolares foram largamente utilizadas como promoção e propaganda da ação dos poderes públicos. Em 1908, o Anuário do Ensino do Estado de São Paulo, registrou todos os edifícios que abrigavam grupos escolares no Estado de São Paulo. Esta coleção de fotografias pertencentes, ao Departamento de Obras do Estado, foi posteriormente repassada para o Instituto Agronômico de Campinas, fazendo parte atualmente do acervo iconográfico do Centro de Memória-Unicamp. Da mesma forma, em 1929, outra obra espetacular foi publicada: o Álbum de Edifícios Escolares do Estado de São Paulo, para ser apresentado na $3^{\text {a }}$ Conferência Nacional de Educação.

Algumas imagens destacam, em primeiro plano, somente o edifício deixando transparecer a arquitetura abstraída das relações sociais. São retratados tanto os edifícios construídos pelo Estado quanto os casarões adaptados para escola. Em outras, figuram também os alunos em segundo plano. Todas elas espelham a escola enquanto lugar, uma instituição merecedora de ser exibida e recordada, seja por sua beleza estética ou pelo seu significado sociocultural.

\footnotetext{
${ }^{3}$ Os primeiros grupos escolares criados no Estado de São Paulo na década de 1890, deviam seguir os moldes da estrutura e método da escola-modelo anexa à Escola Normal da Capital; por esta razão, ficaram conhecidos inicialmente por escolas-modelo.
} 


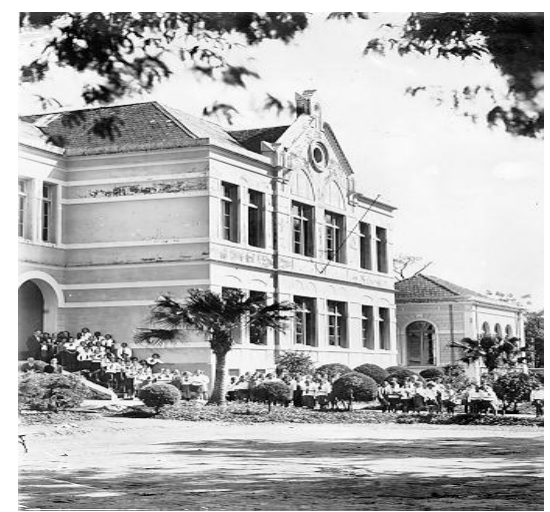

FIGURA 1-FACHADA DO EDIFÍCIO DO $1^{\circ}$ GRUPO ESCOLAR DE CAMPINAS - GRUPO ESCOLAR FRANCISCO GLICÉRIO, DÉCADA DE 1940.

FONTE: Arquivo da EEPG Francisco Glicério, Campinas.

As fotografias do edifício do Grupo Escolar Francisco Glicério são demonstrativas da concepção arquitetônica dos primeiros grupos escolares construídos no Estado de São Paulo. De acordo com a descrição de Woolf:

O projeto do GE de Campinas, visto aqui como um protótipo, limitou-se a agrupar, sobre um porão que se amoldava ao terreno, uma construção de dois pavimentos de volume contido. O programa restringia-se a dois ambientes administrativos e oito salas de aula (4 por andar), dispostas duas a duas ao longo de um eixo de circulação central, paralelo à fachada principal. Os sanitários, numa época em que apenas se iniciavam as instalações de redes públicas de água e esgoto nas cidades do interior, isolavam-se em construções separadas nos fundos dos terrenos, consagrados por gerações de alunos como as "casinhas" (WOOLF, 1992, p. $134)$.

$\mathrm{O}$ andar térreo era destinado à seção feminina e o andar superior à seção masculina. A simetria do edifício correspondia à necessidade da separação entre os sexos e foi mantida nas construções escolares durante toda a Primeira República. Dessa forma, a divisão sexual do espaço vinculava-se a 
uma concepção moral vigente na época. Explica-se, dessa maneira, o porquê da existência de duas entradas laterais separadas.

A demanda por vagas nesta escola sobrepujou desde o início a capacidade física do prédio. Por este motivo, em 1903, foram construídas mais duas salas de aula para o $4^{\circ}$ ano de ambas seções do grupo escolar. Novamente coube a Ramos de Azevedo a adaptação, isto é, a proposição de se construir duas salas de aula térreas, uma de cada lado do edifício em construções independentes, solução que foi incorporada em outros projetos de grupos escolares para outras localidades (WOOLF, 1992, p. 172).

Localizado nas imediações do centro da cidade de Campinas, o grupo escolar, um palacete como era descrito na época, contrastava com as residências e as casas de comércio. Mais que uma casa de instrução, ele informava à sociedade os valores sociais, culturais e morais dos quais se tornava o guardião. O frontão da fachada do edifício foi ornamentado com um relógio revelador de um desses simbolismos, isto é, a escola como uma instituição de ordenação temporal da infância e da vida social.

Por volta de 1910, o edifício do Grupo Escolar Dr. Quirino dos Santos tornou-se cartão-postal, objeto de consumo pronto para ser exibido e admirado. O antigo solar da Viscondessa de Campinas, adaptado para a escola em 1907, apresentava uma bela arquitetura, além de mostrar um cenário habitual de entrada dos alunos na escola. A propósito da relevância do cartãopostal, Fabris assinala:

\footnotetext{
Instrumento de democratização do conhecimento numa sociedade liberal, que acredita no poder positivo da instrução, o cartão postal leva às últimas conseqüências a "missão civilizadora", conferida à fotografia por sua capacidade de popularizar o que até então fora apanágio de poucos. A viagem imaginária e a posse simbólica são as conquistas mais evidentes de uma nova concepção do espaço e do tempo, que abole as fronteiras geográficas, acentua similitudes e dissimilitudes entre os homens, pulveriza a linearidade temporal burguesa numa constelação de tempos particulares e sobrepostos (FABRIS, 1991, p. 35).
}

Nas primeiras décadas republicanas, a escola primária, em particular os grupos escolares, tornou-se símbolo do progresso social e cultural dos núcleos urbanos. O cartão-postal evidenciava o prestígio da instituição. Servia, assim, para o consumo dos pais, alunos e professores da escola, o espaço de recordações afetivas. Para a sociedade campineira, este cartãopostal consistia em uma representação do progresso da cidade. Representação 
que se articulava e se comparava com outros edifícios escolares e outras vistas de outras cidades e regiões. Portanto, a escola como cartão-postal tornava-se um símbolo de civilização.

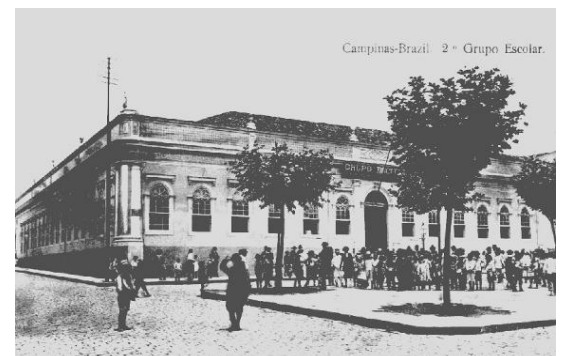

FIGURA 2-CARTÃO-POSTAL: $2^{\circ}$ GRUPO ESCOLAR DE CAMPINAS, GE DR.

QUIRINO DOS SANTOS, DÉCADA DE 1900

FONTE: Centro de Memória - Unicamp, Campinas.

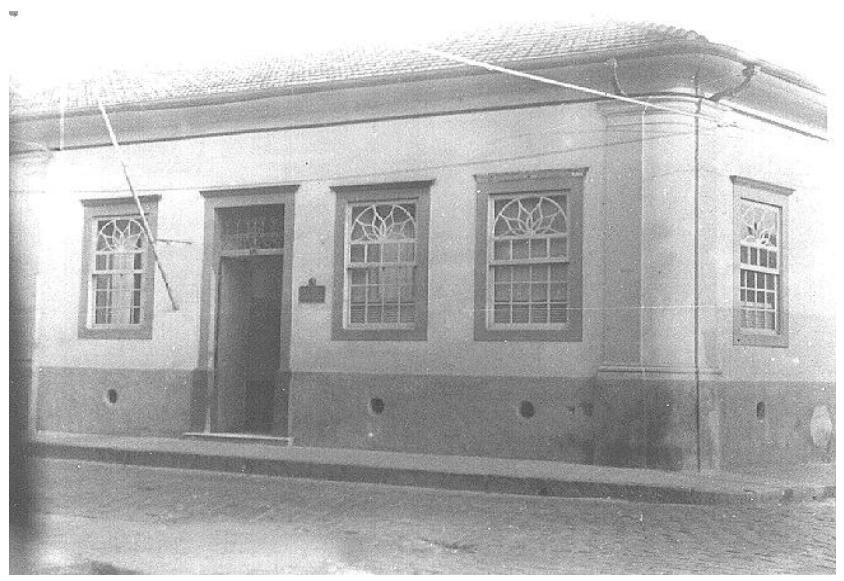

FIGURA 3-FACHADA DO EDIFÍCIO DO $3^{\circ}$ GRUPO ESCOLAR DE CAMPINAS, GE ARTUR SEGURADO, DÉCADA DE 1930.

FONTE: Arquivo da EEPG Artur Segurado, Campinas. 
No velho casarão da rua Dr. Quirino esquina com a rua Barreto Leme, funcionou até 1951, o Grupo Escolar Artur Segurado (3 Grupo Escolar de Campinas). O edifício arrendado pelo Estado foi adaptado para as funções escolares. As fotografias encontradas no arquivo da escola não contêm nenhuma identificação. No entanto, evocam um tempo significativo da história dessa escola, quarenta anos cravada no coração da cidade, até ser transferida para o prédio próprio onde se situa até o presente.

Entre outras imagens, a do antigo edifício busca perpetuar vestígios da história da instituição. O prédio foi demolido, porém sua imagem fixada na fotografia recria espaços da cidade e testemunha suas transformações.

Com exceção do Grupo Escolar Francisco Glicério e do Grupo Escolar Orozimbo Maia, os demais grupos escolares de Campinas funcionaram durante a primeira metade do século $\mathrm{XX}$ em prédios alugados e adaptados para a escola. A situação não era diferente em outros centros urbanos do Estado, que enfrentou durante décadas o problema político e econômico das construções escolares.

A partir de 1905, começaram a surgir em São Paulo os projetos de grupos escolares de um só pavimento considerados menos onerosos que as edificações anteriores. Alguns em forma quadrangular formavam um pátio interno em torno do qual erigia uma galeria de circulação coberta interligando as salas. Outros compreendiam apenas um bloco consistindo em edificações mais simples. Mesmo assim, apesar da perda da monumentalidade, a arquitetura dos grupos escolares manteve a identidade desses estabelecimentos de ensino.

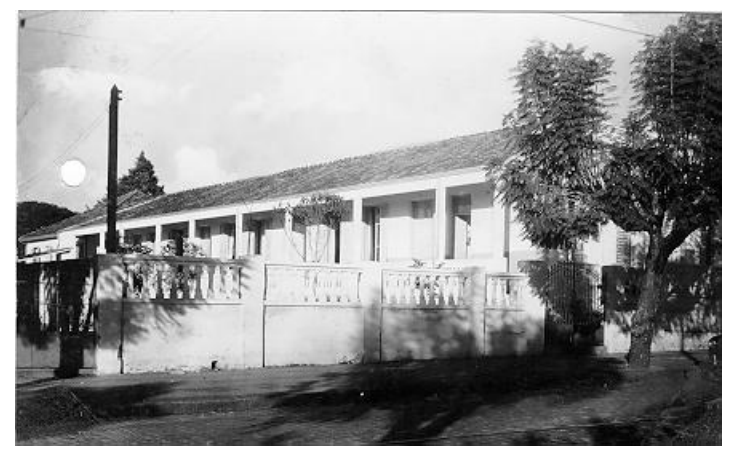

FIGURA 4-FACHADA DO EDIFÍCIO DO GRUPO ESCOLAR DOM BARRETO, DÉCADA DE 1950.

FONTE: Arquivo da EEPG Dom Barreto, Campinas. 
A fotografia acima, do Grupo Escolar Dom Barreto, é representativa dessa modalidade de construções escolares de baixos custos preponderante em São Paulo nas décadas de 1930 e 1940. O edifício, alugado pelo Estado, foi especialmente construído para a escola em 1928 compreendendo seis salas de aula mais uma sala para a diretoria, outra para o arquivo e portaria. Na década de 1930, o prédio passou por várias reestruturações. Duas novas salas foram construídas em 1936: uma para professores e outra para o arquivo ficando a anterior destinada ao gabinete dentário. Posteriormente foram construídos corredores laterais, mais duas salas de aula e um galpão para onde foram transferidas as privadas. Nesse edifício, o Grupo Escolar Dom Barreto permaneceu durante 52 anos. Durante esse tempo, fez parte da paisagem do bairro e tornou-se presente nas recordações de ex-alunos, professores e comunidade escolar, até ser transferido para um prédio próprio. A demolição do antigo prédio da Avenida da Saudade ocorreu em 1984.

\section{Classes de alunos: imagens de uma identidade coletiva}

A maior parte do acervo aqui analisado compreende fotografias de classes escolares referentes às das décadas de 1920 a 1940. Tiradas geralmente ao ar livre, surpreende a padronização do enquadramento e da

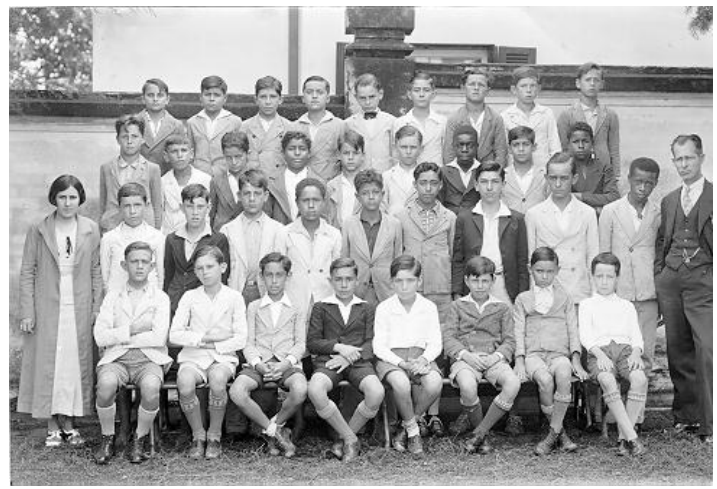

FIGURA 5-TURMA DE ALUNOS DO GRUPO ESCOLAR OROZIMBO MAIA, DÉCADA DE 1930.

FONTE: Arquivo da EEPG Orozimbo Maia, Campinas 
composição das imagens. A fotografia de classes escolares constitui um gênero de fotografia muito popularizado e facilmente reconhecível.

Classes masculinas e classes femininas registram a divisão sexual predominante no ensino público até o início dos anos de 1970, motivada e mantida por princípios morais.

A representação contida nessas imagens é a expressão da ordem escolar. É possível que a disposição em fileiras sucessivas, na primeira um grupo de alunos sentados e nas outras em pé, cada uma sobrepondo-se à outra, tenha sido uma solução técnica para o enquadramento de um grande número de crianças. Esta disposição tão difundida, torna inconfundível uma foto de classe. O grupo é quase sempre acompanhado da professora ou do professor que se posiciona ao lado ou no meio da turma. Em algumas imagens encontrase, também, o diretor da escola. Dessa forma, as fotografias de classes reproduzem a estrutura essencial da escola graduada - grupos escolares. As relações de hierarquia e poder que une os vários membros do grupo retratado, diretor-professores-alunos, mantêm-se na representação da classe, esta unidade de racionalização escolar baseada na classificação dos alunos e na divisão do trabalho e que possibilitou a escolarização em massa. Na prática de divisão das escolas em classes/séries, são dissolvidas as individualidades e sobressai o grupo enquanto identidade coletiva: 1 . $^{\mathrm{a}}, 2 .^{\mathrm{a}}, 3$. $^{\mathrm{a}}, 4 .^{\mathrm{a}}$ série A, B,C, D

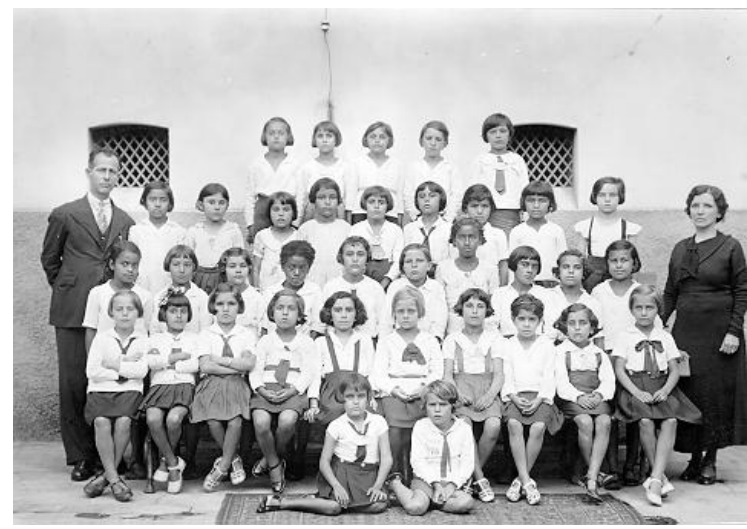

FIGURA 6-TURMA DE ALUNAS DO GRUPO ESCOLAR OROZIMBO MAIA, DÉCADA DE 1930.

FONTE: Arquivo da EEPG Orozimbo Maia, Campinas.

Neste sentido, a classe recria a própria escola e o sentido de ser aluno. A recordação da classe é um microcosmo dos afetos e desafetos com o 
grupo de convivência. É uma recordação dessa identidade coletiva, em que cada um se reconhece como parte (aluno) e o todo (a classe), restitui a dimensão simbólica da instituição escolar.

A classe manifesta, também, a condição social homogênea do grupo e um padrão de comportamento ligados a um enquadramento moral. A origem operária e de setores populares é um traço da condição social dos alunos dos grupos escolares perceptível nas imagens. Os traços físicos e o vestuário são denotativos. Em algumas fotografias, crianças descalças aparecem na segunda fileira. Mesmo com a adoção do uniforme padronizado a partir da década de 1930, estas características permanecem.

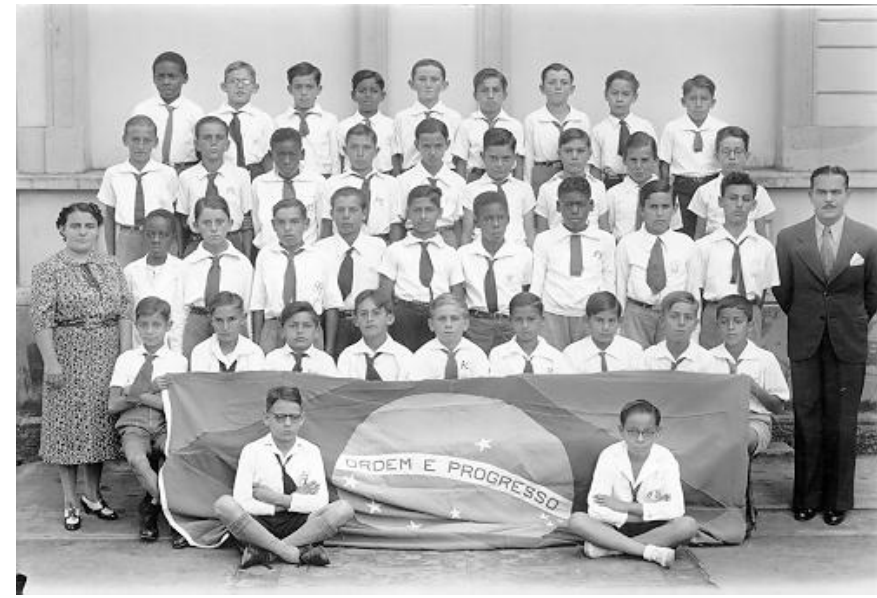

FIGURA 7-TURMA DE ALUNOS DO GRUPO ESCOLAR FRANCISCO GLICÉRIO, DÉCADA DE 1950.

FONTE: Arquivo da EEPG Francisco Glicério, Campinas.

As imagens revelam a presença de crianças negras nas classes dos grupos escolares. Este dado, desconsiderado nos registros escolares, apresenta-se como uma informação interessante e de fundamental importância para a história da educação em geral e dos negros no Brasil. Eles são em pequeno número: um, dois, três em cada turma. As imagens retratam, portanto, a exclusão social do negro na educação.

Brancos e negros, filhos de imigrantes ou não, são submetidos aos mesmos padrões morais, às mesmas normas de urbanidade e civilidade. As fotografias de classe expressam este comportamento desejável. Nas imagens, o ar de respeito, de seriedade, de gravidade. Poucas crianças emitem um sorriso furtivo. Pernas juntas, os braços cruzados ou estendidos. A pose para a 
fotografia da classe consiste, na primeira metade do século XX, em um ritual de compenetração. A escola é o espaço da ordem, da obediência, do silêncio e da disciplina, cuja representação é confirmada nesse tipo de imagem.

\section{Corpo docente dos grupos escolares: vestígios de uma cultura profissional}

$\mathrm{Na}$ memória e história das instituições educativas, diretores e professores são lembrados pelo trabalho, a dedicação e a colaboração prestada às escolas e à comunidade (gerações de crianças).

No início do século XX, o magistério primário estava constituindo-se enquanto categoria profissional. $\mathrm{O}$ valor atribuído à escola pública dignificou a profissão docente e o professor passou a ser considerado o "apóstolo da instrução" - o profissional responsável pela mais nobre missão, isto é, a formação do cidadão republicano. Apesar dos baixos salários, ser professor ou professora era digno de respeito, reconhecimento, admiração.

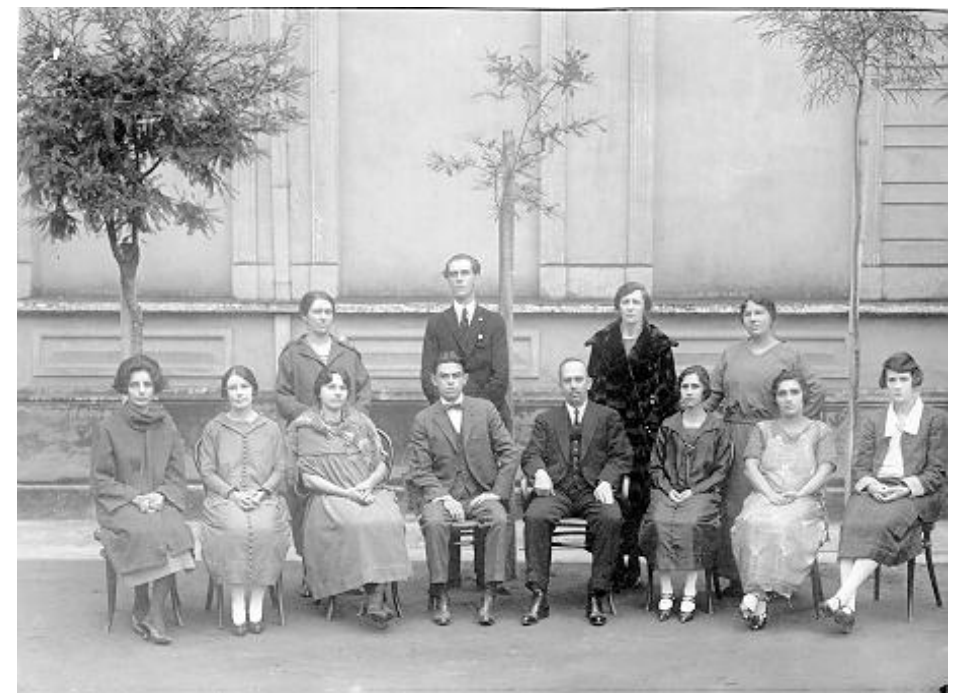

FIGURA 8-CORPO DOCENTE DO GRUPO ESCOLAR FRANCISCO GLICÉRIO, DÉCADA DE 1900.

FONTE: Arquivo da EEPG Francisco Glicério, Campinas.

Nessa época, os grupos escolares eram tidos como uma inovação educacional recente e de prestígio. Eram consideradas escolas públicas 
modelares e de excelência. $\mathrm{O}$ valor social atribuído a essas escolas perdurou por muitas décadas, apesar da massificação da escola primária a partir de 1920 e o conseqüente recrudescimento da qualidade do ensino.

Em Campinas, os primeiros grupos escolares buscaram consolidar essa representação reafirmando a qualidade dos serviços prestados à população. Em torno disso erigiram a memória e a tradição da escola.

A história das instituições educativas não pode, portanto, desconsiderar os ritos e os símbolos que fazem parte da cultura escolar. De fato, os grupos escolares foram próceres na ostentação de muitos símbolos sociais, especialmente de natureza moral e cívica e cultivaram práticas que contribuíram com a "invenção de tradições", como sugere HOBSBAWM e RANGER (1984), relacionadas com a construção do imaginário sociopolítico republicano.

$\mathrm{Na}$ tentativa de construir uma identidade institucional, essas escolas criaram as suas próprias tradições, por exemplo, o culto ao patrono e a comemoração do aniversário de criação/instalação do estabelecimento de ensino, a memória dos primeiros diretores, professores e ex-alunos que ganharam visibilidade pública.

Os primeiros professores e diretores dos grupos escolares de Campinas compreendem uma plêiade de homens e mulheres ilustres a quem as escolas reverenciam. Dessa forma, reportam-se à fundação, às origens da instituição.

Em alguns grupos escolares como o GE Francisco Glicério, Ge Orozimbo Maia e GE Dom Barreto, encontram-se álbuns de fotografias, caprichosamente decorados, contendo retratos dos primeiros diretores e professores, além de uma pequena biografia.

No retrato, destaca-se a individualidade, a expressão de qualidades e virtudes incontestáveis, dignas de eternização. Os retratos do patrono e de iminentes diretores da escola pendurados na parede são demonstrativos. Nos álbuns escolares, o retrato inspira a memória de cada um dos mestres que doaram anos de trabalho e dedicação à causa da instrução pública.

Não obstante, a fotografia do corpo docente já não se reporta à galeria dos memoráveis. Diferentemente do retrato individual, estas imagens referem-se à identidade coletiva dos professores como corpus. Elas transformam o indivíduo professor em uma categoria profissional e institucional. Distinção, respeito, galhardia depreendem-se nessas imagens. O ar grave e austero é expressão do ofício profissional. 


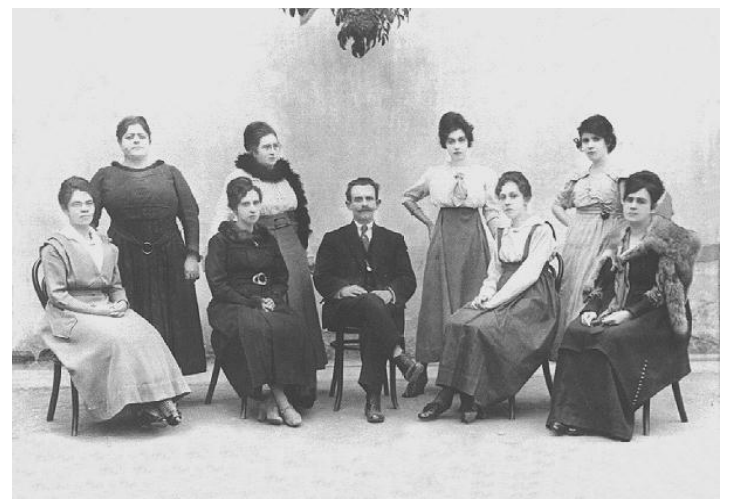

FIGURA 9-CORPO DOCENTE DO GRUPO ESCOLAR ARTUR SEGURADO, 1910. FONTE: Arquivo do Centro de Memória - Unicamp, Campinas.

O grande número de mulheres em relação ao reduzido número de professores do sexo masculino registra o que foi a composição do magistério primário no Brasil desde o final do século XIX. O diretor ocupa o lugar central na fotografia, reproduzindo na imagem as relações de poder prevalecentes na organização escolar. $O$ diretor, quase sempre do sexo masculino, até meados do século XX, reflete a divisão sexual do trabalho

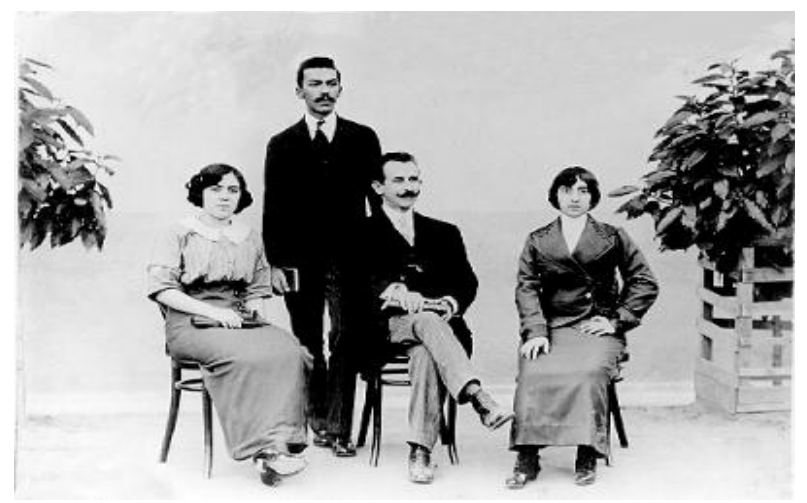

FIGURA 10-CORPO DOCENTE DO GRUPO ESCOLAR ARTUR SEGURADO, 1910. FONTE: Arquivo do Centro de Memória - Unicamp, Campinas. 
também no magistério o que também pode ser observado nas imagens retratando reuniões de autoridades do ensino público.

$\mathrm{Na}$ foto do corpo docente do Grupo Escolar Artur Segurado ( $\left.3^{\circ} \mathrm{GE}\right)$, destaca-se a presença de um professor negro. Nesse caso, a imagem possibilita identificar e desmistificar a composição racial do magistério.

\section{Práticas escolares: reminiscências do ensino primário}

Algumas imagens do acervo reunido durante a pesquisa retratam eventos e atividades escolares. Essas fotografias são bastante significativas para a compreensão da cultura escolar predominante nas escolas primárias.

As salas de aula são ambientes pouco retratados. Porém, foram encontradas no arquivo da EEPG Orozimbo Maia, cinco imagens reproduzindo atividades em sala de aula. A pose exagerada representa uma caricatura da disciplina escolar - braços para trás, postura ereta nas carteiras, olhar atento, silêncio.

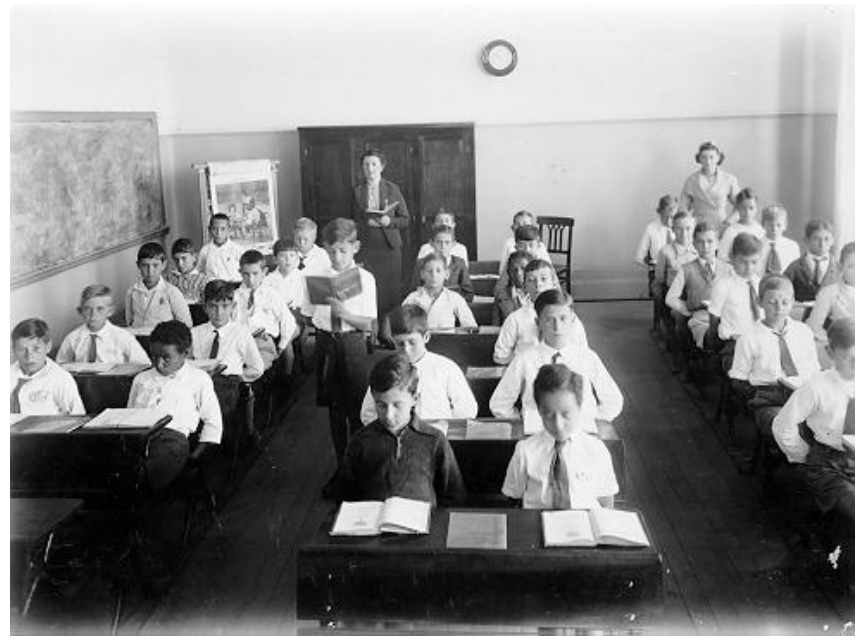

FIGURA 11-AULA DE LEITURA, SEÇÃO MASCULINA DO GRUPO ESCOLAR OROZIMBO MAIA, 1939.

FONTE: Arquivo da EEPG Orozimbo Maia, Campinas. 
$\mathrm{Na}$ aula de leitura, de uma seção masculina, o olhar dos alunos que deveriam se deter no livro se desloca para a câmera, mas o cenário enquadra o comportamento típico. Práticas de leitura podem ser observadas na postura da professora e sua auxiliar e na do aluno que lê em pé seguindo todas as prescrições para uma boa leitura oral - corpo ereto, pernas juntas, uma das mãos segura o livro à altura do peito, a outra descansa atrás. A leitura sem qualquer auxílio a não ser os olhos é uma habilidade treinada diariamente na escola.

O espaço da classe também representa o padrão típico presente nos grupos escolares: sala retangular, lousas na frente da sala e em uma das paredes laterais, carteiras duplas fixas ao solo, no fundo um relógio, um armário e um cavalete contendo cartazes referentes à lição do dia.

Numa seção feminina, o destaque é para a aula de geografia. A câmera flagra o olhar desatento das alunas que se voltam para ela enquanto a professora e uma aluna permanecem frente ao quadro negro totalmente desenhado.

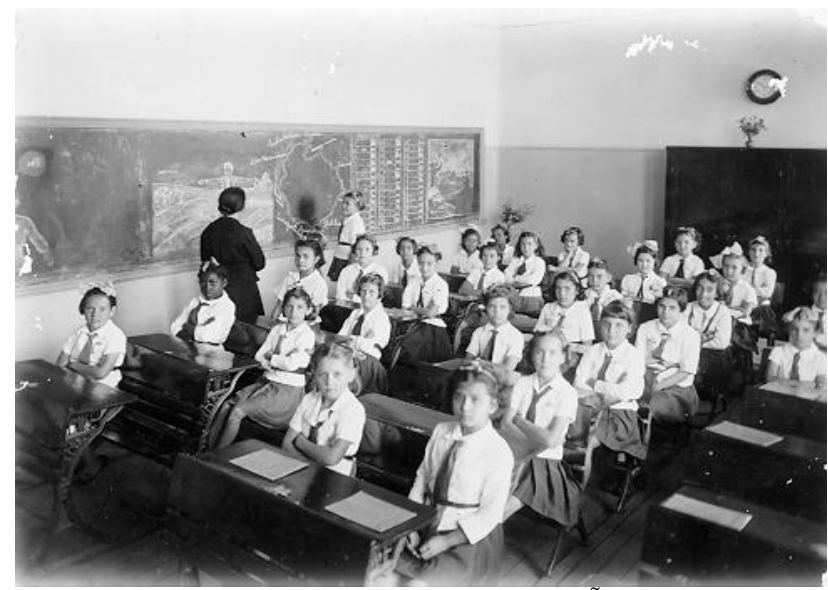

FIGURA 12-AULA DE GEOGRAFIA, SEÇÃO FEMININA DO GRUPO ESCOLAR OROZIMBO MAIA, 1939.

FONTE: Arquivo da EEPG Orozimbo Maia, Campinas.

$\mathrm{Na}$ aula de Língua Portuguesa, seção feminina, sobressai o ensino de caligrafia. Os cadernos estão sobre as carteiras. Na lousa a professora acompanha duas alunas que exercitam atividades de coordenação motora e reconhecimento da letra $\mathrm{G}$ em maiúscula e minúscula. No fundo da classe, um cavalete contém o mapa do Estado de São Paulo. De braços cruzados, o olhar 
abaixado, poucas meninas se atrevem a olhar para a câmera fotográfica. A artificialidade da cena fixa, não obstante, o ideal de uma aula de língua pátria.

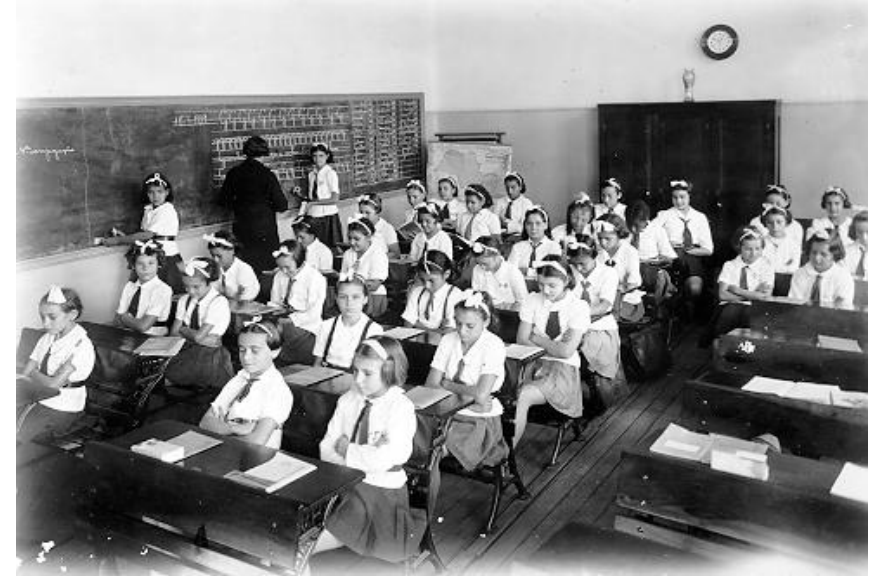

FIGURA 13-AULA DE LÍNGUA PORTUGUESA, SEÇÃO FEMININA GRUPO ESCOLAR OROZIMBO MAIA, 1939.

FONTE: Arquivo da EEPG Orozimbo Maia, Campinas.

A aula de matemática é retratada em outra classe da seção masculina. Três alunos estão no quadro negro resolvendo exercícios, um deles usa um grande compasso. No fundo da sala, em pé, a professora e sua auxiliar. Alguns

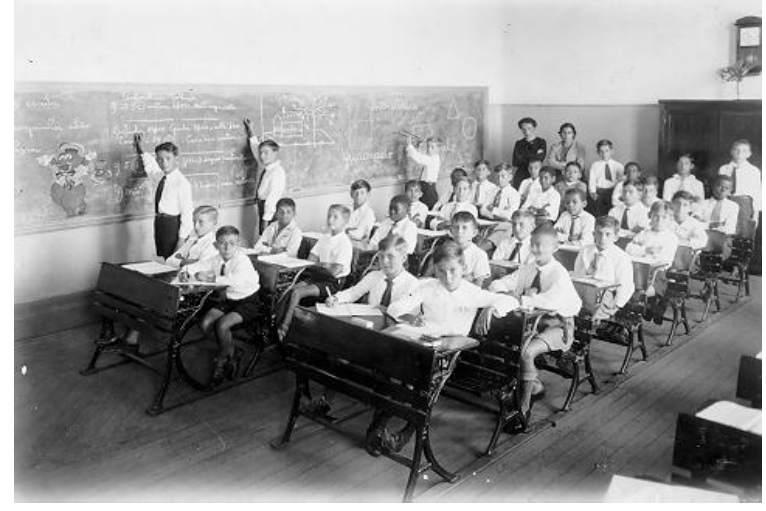

FIGURA 14-AULA DE MATEMÁTICA, SEÇÃO MASCULINA DO GRUPO ESCOLAR OROZIMBO MAIA, 1939.

FONTE: Arquivo da EEPG Orozimbo Maia, Campinas. 
alunos a acompanham, também em pé, para saírem na fotografia que abrange apenas a metade da sala. Alguns alunos seguram o lápis na mão como se estivessem escrevendo. Outros estão com os braços cruzados. A maioria deles olha para a câmera.

Mais uma aula da seção masculina tirada do fundo da sala. Todos os alunos estão virados para o quadro, todo escrito com lições de geografia. A professora na frente da sala, próxima à sua mesa, acompanha o aluno que se encontra de pé em frente ao quadro. Sobre a lousa sobressai a bandeira nacional, motivo também estampado no cartaz que se encontra sobre o cavalete.

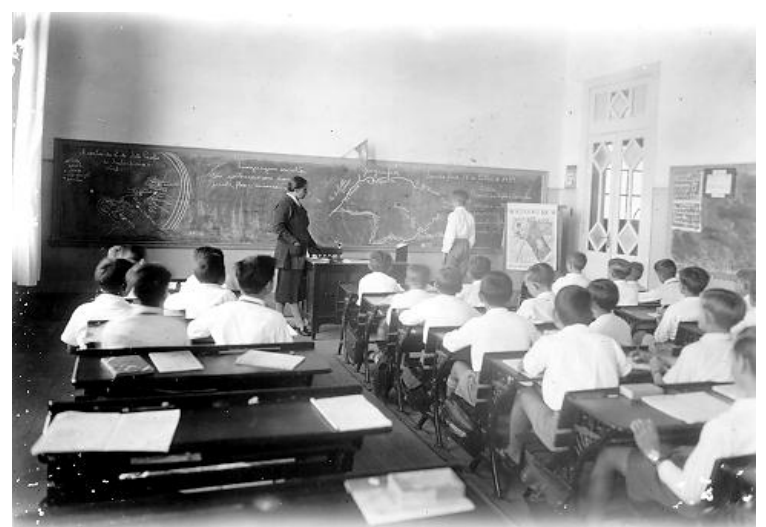

FIGURA 15-AULA DE GEOGRAFIA, SEÇÃO MASCULINA DO GRUPO ESCOLAR OROZIMBO MAIA, 1939.

FONTE: Arquivo da EEPG Orozimbo Maia, Campinas.

O que teria levado à produção dessas imagens? Teriam consistido em um registro das atividades da escola? Seria uma nova modalidade de recordação escolar?

Também fazem parte do acervo em análise algumas fotografias retratando aulas de educação física.

A disciplina educação física passou a compor os programas do ensino primário do Estado de São Paulo, na última década do século XIX, sob a rubrica "ginástica e exercícios militares". Enfatizada pela sua influência moralizadora e higiênica, tinha por finalidade tornar os corpos ágeis, robustos e vigorosos, desenvolvendo no aluno a coragem e o patriotismo. Inicialmente, prevaleceu o uso de aparelhos combinado com exercícios calistênicos, dados especialmente nas salas de aula entre uma matéria e outra. No ginásio ou ao ar livre, eram indicadas marchas, corridas e jogos ginásticos. 
No acervo do Centro de Memória - Unicamp, na coleção do Instituto Agronômico, encontra-se uma interessante imagem de uma aula de ginástica da seção masculina do Grupo Escolar Francisco Glicério ( $1^{\circ}$ Grupo Escolar de Campinas) referente à década de 1900. Nessa coleção, encontram-se fotografias encomendadas pelos órgãos da administração pública para servirem de registro, de comprovação das obras e melhoramentos empreendidos pelo Estado. Essas imagens foram utilizadas também como forma de propaganda da ação oficial. Possivelmente, a fotografia mencionada tenha sido produzida com esta finalidade.

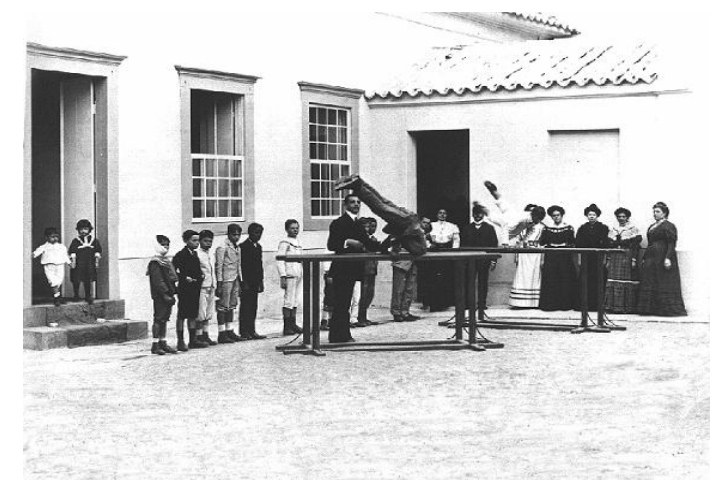

FIGURA 16-AULA DE GINÁSTICA, SEÇÃO MASCULINA DO GRUPO ESCOLAR FRANCISCO GLICÉRIO, DÉCADA DE 1900.

FONTE: Arquivo do Centro de Memória - Unicamp, Campinas.

A imagem busca representar uma aula de ginástica mediante o uso de aparelhos. Assim, no primeiro plano, sobressaem os aparelhos e dois alunos exercitando-se neles. Ao lado, alguns alunos observam e o professor acompanha a atividade. Ao fundo, permanece um grupo de professoras.

A partir da década de 1920, os programas de educação física para o ensino elementar foram redefinidos em torno das práticas esportivas que minimizavam os sofrimentos dos exercícios físicos, tornando a educação física mais prazerosa para as crianças. O programa adquiriu, portanto, uma feição mais flexível e prática, incluindo brincadeiras do universo infantil, jogos ginásticos, corridas, saltos e marchas. 
A atuação da inspetora de educação física, Ottília Forster, junto aos grupos escolares de Campinas foi marcante na década de 1940. As imagens reunidas no acervo destacam seções masculinas e femininas dos Grupos Escolares Francisco Glicério, Orozimbo Maia e Dom Barreto sob a coordenação da citada inspetora, acompanhada dos respectivos diretores.

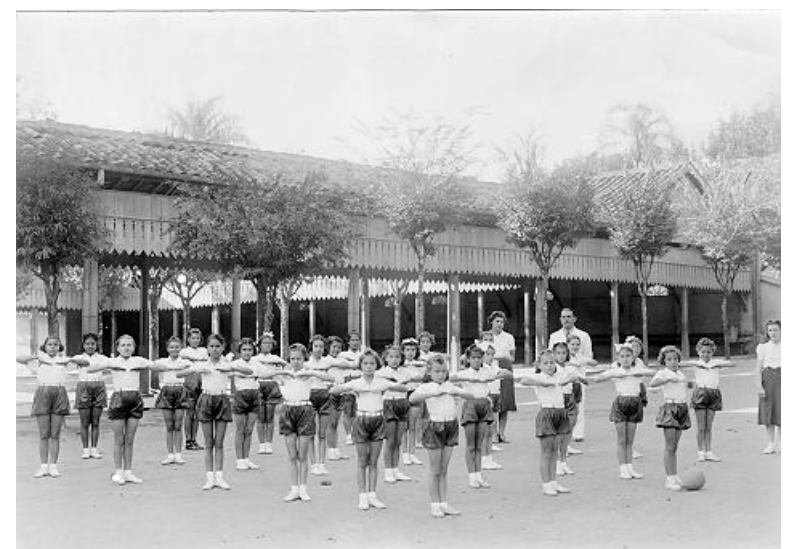

FIGURA 17-AULA DE EDUCAÇÃO FÍSICA, SEÇÃO FEMININA DO GRUPO ESCOLAR FRANCISCO GLICÉRIO, DÉCADA DE 1950. FONTE: Arquivo da EEPG Francisco Glicério, Campinas.

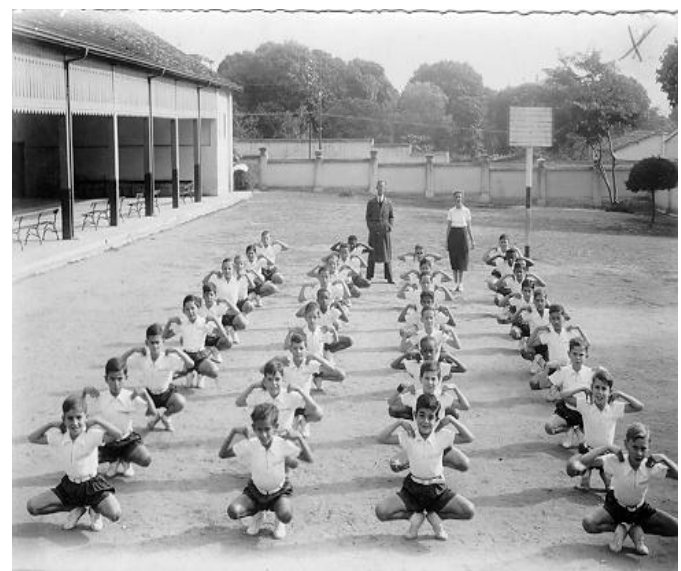

FIGURA 18-AULA DE EDUCAÇÃO FÍSICA, SEÇÃO MASCULINA DO GRUPO ESCOLAR OROZIMBO MAIA, DÉCADA DE 1950. FONTE: Arquivo da EEPG Orozimbo Maia, Campinas. 
Devidamente uniformizados e dispostos em filas, cada uma das classes retratadas exibem um movimento. Harmonia, ordem, regularidade e simultaneidade de ritmos transparecem nas imagens.

As fotografias de aulas de educação física revelam a forma escolar de investimento no corpo. No universo das práticas escolares, essa atividade é uma das que mais simbolizam a função moralizadora e disciplinar da escola primária.

As fotografias de eventos escolares - festas, exposições e comemorações - são contributos para a memória institucional. Neste acervo, destaca-se uma imagem singular. Ela retrata uma exposição escolar, certames realizados anualmente nas escolas públicas destinadas à exibição dos trabalhos escolares, especialmente aqueles produzidos pelos alunos na disciplina Trabalhos Manuais. Trata-se, portanto, do registro de uma prática ritualizada. A realização conjunta da exposição pelos grupos escolares Francisco Glicério e o $6^{\circ}$ Grupo Escolar de Campinas (Dom Barreto) talvez tenha motivado a produção da fotografia.

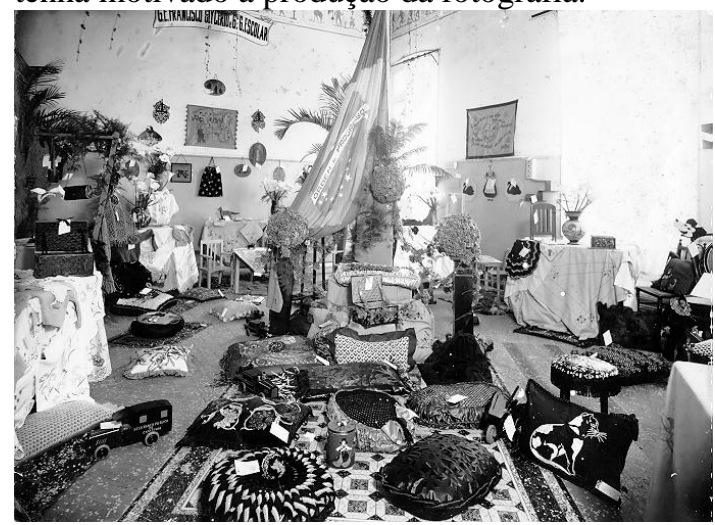

FIGURA 19-EXPOSIÇÃO ESCOLAR CONJUNTA DOS GRUPOS ESCOLARES FRANCISCO GLICÉRIO E BARRETO, DÉCADA DE 1930.

FONTE: Arquivo da EEPG Francisco Glicério, Campinas.

Tomadas como fonte de pesquisa para a história da escola primária, as fotografias escolares são mais que um testemunho, mais que uma evocação. Como observa LEITE (1993), a "intensidade expressiva" da imagem não é redutível a palavras. Neste sentido, este texto compreende um exercício de leitura de imagens escolares, uma tentativa de explorar e dar voz a esses "pedaços congelados do passado em forma de imagens" (KOSSOY, 1998). Assim, o acervo reunido durante a pesquisa constitui, a um só tempo, um conjunto de fontes iconográficas e resultado de pesquisa. Tais imagens 
exibem fortes impressões de uma escola primária dotada de identidade e cultura próprias.

As fotografias dos grupos escolares de Campinas constituem, portanto, um interessante acervo de memória da escola primária no Estado de São Paulo. Testemunhas de um passado notável, essas imagens cultuam uma memória e interrogam o presente. Não restaria algo a aprender com este modelo de escola?

\section{REFERÊNCIAS}

BARROS, A. M. Educando o olhar: notas sobre o tratamento das imagens como fundamento na formação do pedagogo. In: SAMAIN, Etienne (org.) $O$ Fotográfico. São Paulo: Hucitec/CNPq, 1998.

BARROS, A.M. O tempo da fotografia no espaço da História: poesia, monumento ou documento? In: NUNES, C. O passado sempre presente. São Paulo: Cortez, 1992.

CARVALHO, M. C. W. e WOLFF, S. F. S. Arquitetura e fotografia no século XIX. In: DELSAUT, Yvette. Une photo de classe. In: Carneis de Socionalyse, n. 2, s/d, p. 83-96, [19-]

COMO organizar um arquivo fotográfico. Fase, Rio de Janeiro, 1988.

FABRIS, A. (org.) Fotografia: usos e funções no século XIX. São Paulo: Edusp, 1991.

FABRIS, A. A Invenção da Fotografia: repercussões sociais. In: FABRIS, A. (org.) Fotografia: usos e funções no século XIX. São Paulo: Edusp, 1991.

GONÇALVES, C. D.; LEÃO, F. C. Os retratos fotográficos de Geraldo Sesso Junior. In: Boletim do CMU, v. 5, n. 10, 1993, p. 89-100, 1993.

KOSSOY, B. Fotografia e História. São Paulo: Ática, 1995.

KOSSOY, B. Fotografia e memória: reconstituição por meio da fotografia. In: SAMAIN, Etienne (org.) O Fotográfico. São Paulo: Hucitec/CNPq, 1998.

LANG, A. B. S.G. (Org.) Documentos e depoimentos na pesquisa históricosociológica. In: CERU. Reflexões sobre a pesquisa sociológica. São Paulo: CERU, 1992, p. 117-141. 
LE GOFF, J. História e Memória. Campinas: Ed. da Unicamp, 1990.

LEITE, M. L. M. Retratos de família: imagem paradigmática no passado e no presente. In: SAMAIN, E. (Org.) O fotográfico. São Paulo: Hucitec/CNPq, 1998.

LEITE, M.L. M. Fotografia de Família. In: Cadernos Ceru, n. 18, p. 79-89, 1983.

LEITE, M.L. M. Imagens e Contextos. In: Boletim do CMU, v. 5, n. 10, p. 4560, 1993.

LEITE, M.L. M. Retratos de Família. São Paulo: Edusp/Fapesp, 1993.

LIMA, S. F. O circuito social da fotografia: estudo de caso II. In: FABRIS, A. (Org.) Fotografia: usos e funções no século XIX. São Paulo: Edusp, 1991.

MAGALHÃES, J. Contributo para a História das Instituições Educativas entre a memória e o arquivo. In: REUNIÃO NACIONAL DA ANPED, 19., Caxambu. Anais... Caxambu: Anped, 1996. Mimeog.

OLIVEIRA, L. L. As festas que a República manda guardar. Estudos Histórico, Rio de Janeiro, p. 172-189, 1989.

SONTAG, S. Ensaios sobre fotografia. Lisboa: Dom Quixote, 1986.

SOUZA, R. F. Templos de Civilização: a implantação da escola primária graduada no Estado de São Paulo (1890-1910). São Paulo: Ed. da Unesp, 1998.

SOUZA, R. F. Educação e Tradição: EEPG Francisco Glicério de Campinas 1897-1997. Araraquara: FCL, 1997.

WOOLF, S. F. S. Espaço e Educação: os primeiros passos da arquitetura das escolas públicas paulistas. São Paulo, 1992. Dissertação (Mestrado em Arquitetura) - Faculdade de Arquitetura, Universidade de São Paulo. 